\title{
Generic Costing Scheme Using General Equilibrium Theory for Fair Cloud Service Charging
}

\author{
Masnida Hussin*, Siti Fajar Jalal, and Rohaya Latip \\ Department of Communication Technology and Networks \\ Faculty of Computer Science and Information Technology \\ University of Putra Malaysia, 43400 UPM Serdang, Selangor, Malaysia \\ [e-mail:masnida@upm.my, fajarupm@gmail.com, rohayalt@upm.edu.my] \\ *Corresponding author: Masnida Hussin
}

\begin{abstract}
Cloud Service Providers (CSPs) enable their users to access Cloud computing and storage services from anywhere in quick and flexible manners through the Internet. With the basis of 'pay-as-you-go' model, it makes the interactions between CSPs and the users play a vital role in shaping the Cloud computing market. A pool of virtualized and dynamically scalable Cloud services that delivered on demand to the users is associated with guaranteed performance and cost-provisioning. It needed a costing scheme for determining suitable charges in order to secure lease pricing of the Cloud services. However, it is hard to meet the satisfied prices for both CSPs and users due to their conflicting needs. Furthermore, there is lack of Service Level Agreements (SLAs) that allowing the users to take part into price negotiating process. The users may lose their interest to use Cloud services while reducing CSPs profit. Therefore, this paper proposes a generic costing scheme for Cloud services using General Equilibrium Theory (GET). GET helps to formulate the price function for various services' factors to match with various demands from the users. It is initially determined by identifying the market circumstances that a general equilibrium will be hold and reached. Specifically, there are two procedures of agreement made in response to (i) established equilibrium supply and demand, and (ii) service price formed and constructed in a price range. The SLAs in our costing scheme is integrated to satisfy both CSPs and users' needs while minimizing their conflicts. The price ranging strategy is deliberated to provide prices' options to the users with respect their budget limit. Meanwhile, the CSPs can adaptively charge based on users' preferences without losing their profit. The costing scheme is testable and analyzed in multi-tenant computing environments. The results from our simulation experiments demonstrate that the proposed costing scheme provides better users' satisfaction while fostering fairness pricing in the Cloud market.
\end{abstract}

Keywords: Cloud Services, Costing Scheme, General Equilibrium Theory, Price Fairness, Multi-Tenant Environment 


\section{Introduction}

$\mathbf{T}_{\mathrm{h}}$

he Cloud computing consists of heterogeneous services and varies type of users in terms of their processing requirements. It acts as a resource sharing pool that provides services to multiple users through the Internet that makes service cost varied. Current issue in Cloud environment is the users no longer look into on the processing power and data storage capacity but on service charges [1-5]. The Cloud services that leased to end users are charged using a 'pay-per-use' model $[2,4]$. Therefore, it is the big challenge in Cloud computing to determine suitable price for leasing the services while satisfying processing requirements. Core feature in Cloud service infrastructures is Service Level Agreements (SLAs) that led seamless service at high quality of service to the users. The availability of Cloud service on a continuous basis might be incurring more expense. Cloud computing has a significant market potential, but it needs a pricing model to determine appropriate prices for various Cloud services [5-8]. A payment model is normally determined when, how many and for how long such services are required by the users $[2,5,6]$. There is still a limited solution for pricing determination procedure towards sharing and managing Cloud services especially in terms of suitable payment model [6-8]. Meanwhile, each service provider has its own pricing plan that makes the payment model remain a huge challenge. The users might be demotivated because of the fluctuating service charges that normally controlled by the services provider [2,11-13]. It is necessity for the Cloud providers to understand to what extend the prices and Quality of Service (QoS) level needed to be set for fulfilling demands. The Cloud providers also required to provide transparency in charging the services to the users in order to improve trustworthiness in resource sharing.

Note that, the Cloud Service Providers (CSPs) intention to fulfill users' demands, but it comes with the price charging on the services that leased by the users. Meanwhile, the users rent the services for satisfying task requirements with minimum cost. It raises conflicting in fulfilling the SLAs. Due to the service quotation is made according to the CSPs terms and definitions $[4,5,14]$, the users have limited access in taking parts into the agreement process especially in negotiating the service price. Hence, even though there are sophisticated Cloud services, constrained in 'buy power' from the user's side leads to underutilized services. It further, reduces the CSPs profit and revenue, if not in present-day, it might affect in long run return [4]. Therefore, the costing scheme should be satisfied in both parties i.e., CSPs and users despite their conflicting needs.

We present a generic costing scheme through multi-level agreement procedures between users and service providers that aims for achieving fair service charging. 'Fair' in our work defined as fulfilling both entities' interest and need. Specifically, we analyze providers' initial revenue and users' service requirements, and provided that by both entities must be willing to participate in the Cloud market. We utilized the General Equilibrium Theory (GET) $[9,15]$ in forming the service price where the behavior of supply, demand, and prices are essential attributes in the agreement. Due to the theory assumed that there is a gap between actual prices and equilibrium prices, our pricing is then formed in a range. It means that the exact price for the Cloud service is charged within the established price range. Based on the results from our extensive experiments, our pricing model has demonstrated substantial positive effects on high satisfaction in both users and providers under heterogeneous computing scenarios.

The remainder of this paper is organized as follows. A review of related work on service costing scheme from economic models is presented in Section 2. Section 3 details the models used in the paper. Our pricing formulation through GET is presented in Section 4. 
Experimental settings and results are presented in Section 5. Finally, Section 6 concludes the paper.

\section{Related Work}

A fair charge for Cloud services is a good way of motivating entities in Cloud environment to interact and utilize available services. Inspired by the on-demand services, the 'pay-as-you-go' model has been effectively used and becomes a pricing model in Clouds [4, 6, 13]. Such pricing model is appropriate for Cloud computing where the service availability is not anymore as a big issue. The Cloud services are guaranteed to be accessed and consumed at anytime from anywhere for the users. Normally, the price is determined based on the numbers of CPU, availability of live storage, software license fee, backup and maintenance $[2,3,10]$. There are also additional charges that proposed by the Cloud service providers (CSPs) in offering the services. For example, in the Amazon Web Services the price charging is included for the main services and upfront infrastructure. Some Cloud providers used package of service for charging the users with fix price e.g., in [11-13]. There is also where the Cloud providers offer contract basis pricing approaches $[7,15]$ to the users for leasing their services. Specifically, the pricing agreement is different from one Cloud provider to another. It is not merely because of total capital of Cloud services; the taxes and foreign exchange may also affect the fluctuation of the service price.

We notice the fact that research on price competition amongst Cloud providers is not new in the economic domains. Market competition between Cloud providers is a vital factor in capacity planning because the providers set prices primarily to make profits $[1,7,10]$. Basically, the prices that they set had influenced on demands from end-users, where their demands led to the provisioning of optimal resource capacities. The authors in [1] used Nash equilibrium strategy to pave the path for Cloud provider identified the service prices and Quality of Service (QoS) level that can be set for users. They utilized the concept of game theory that involved several players/providers in the active game that assumed each provider knew the equilibrium strategy of other providers. Their multiple Nash equilibrium exists for the price vectors for the simultaneous price - QoS game. In [15], the authors proposed the catalogue-based pricing Cloud services in order to identify resource (supply) characteristics. From such information, they formulate several processing conditions in order to compute the price of processing demands. The price is charged depend on the total amount of service request over available resources. Meanwhile, the authors in [16] employed financial option theory and treat the Cloud resources as real assets. It aims to capture the realistic value of the Cloud services. Their method is similar in our work in regards the maximum and minimum values of prices that needs to be determined prior to identify the exact price.

Despite economical basis approaches used in designing the Cloud costing scheme, there are three different pricing methods used (i) pricing for provider's profit, (ii) pricing for user's utility and (iii) equilibrium pricing. In response to the issue in determining the right prices for improving the profit, the variance-based pricing is proposed by the authors in [17]. In their pricing scheme, the providers' competitors have influenced in determining the range of service price. The variance-based pricing is generated to ensure the provider's service costs are close or similar with other providers. The price then offered to the users without refers to the variability of the users' demand. However, at the same time it supports equilibrium market. Meanwhile, the researchers in [18] introduced the spot market as one of the markets' behaviours in their work, besides pay-as-you-go (PAYG) and on-demand (OD) markets. The 
spot market provides useful information on the users' willingness to pay for the Cloud services. The market offers negotiable platform for the users to pay less if it turns their request is satisfied, but it must be higher than initial cost as to prevent from negative provider's profit.

There are studies concerned on the users' preferences, as proposed in [19] where they designed the well-planed and informative costing guidelines for making the users understand associated cost in Cloud computing. Their costing guidelines leads to better service level agreement (SLAs) that proven in the users' satisfaction. For fulfilling the users' requirements, the SLAs is significant to consider user's utility functions or can be refers as user's subjective satisfaction, happiness, and perception of worthiness [20]. The authors in [20] proposed price profiling from the available services. They modelled six utility functions satisfaction based on categories of Cloud services are High Availability (HA), Disaster Recovery (DR), Hosting, VDI, Content delivery, terminal servers, and Big data. It might give better understanding to the user on how the costing scheme works in Cloud environment. However, there are diverse type of Cloud application available that make it is hard to profile the suitable price.

Satisfying user needs and expectations while accommodating the provider' profits is another focuses in designing the costing scheme. Such pricing focuses can be referred as equilibrium price where the demand and supply become significant attributes in justifying the service price. The authors in [21] proposed robust deterministic approximation models to construct efficient heuristic fixed-price pricing policies. While guaranteeing the worst-case revenue of the providers, their work considers the users' willingness in accepting the price function. Hence, it reduces the number of users that rejected the offered price. In [22], the authors proposed the time slot for the users to request the available services with cost preferences, either monetary cost (i.e., service price) and non-monetary cost (i.e., service waiting time). In their work, the agent will be used to perform negotiation process where the successful providers in fulfilling the users' request will be given a reward. It improves the providers' reputation which leads to have more numbers of buyer in the market. Another work that considered both market entities (i.e., providers and users) is from the authors in [4]. The providers in their work are assumed as monopoly providers where the costing scheme is determined prior. They also considered the demand from the users where they introduced the users' reservation price to be matched with the provider's subscription pricing. Specifically, our work is fall into the equilibrium pricing type.

\section{Models}

In this section, we describe the market and Cloud service infrastructure used in our study.

\subsection{The Market}

The proposed market (Fig. 1) used in this study is considered interdependent system that offer economy-wide interaction among its entities. It is composed the interaction between Cloud users, price coordinator and service providers. The users comprise of set $n$ users that are loosely connected by a communication network, and each request for the different service requirements. They requested either for storage or CPU where each is associated with a set of preferences, given as expected rental duration, task requirement and budget limit.

Meanwhile, there are resources/services from the providers that always available in the market. The service providers are served services for the users where each service has a reserve value. The value is related to resource specification e.g., cost, capacity, and reliability. Each provider mainly aims for increasing its profit from the services that leased by the users. The 
Cloud price coordinator acts as intermediate part that attached to users and providers through communication network. The main role of coordinator (Fig. 1) in our study is to identify a suitable service price range. The coordinator aggregates demand-and-supply information from users and providers to provide GET-based price charging process. The price range takes into account both users' demands and providers' supplies for adaptively adjusting between the users' budgets and providers' profits. The coordinator then response to the users and providers by exporting the agreeable price range.

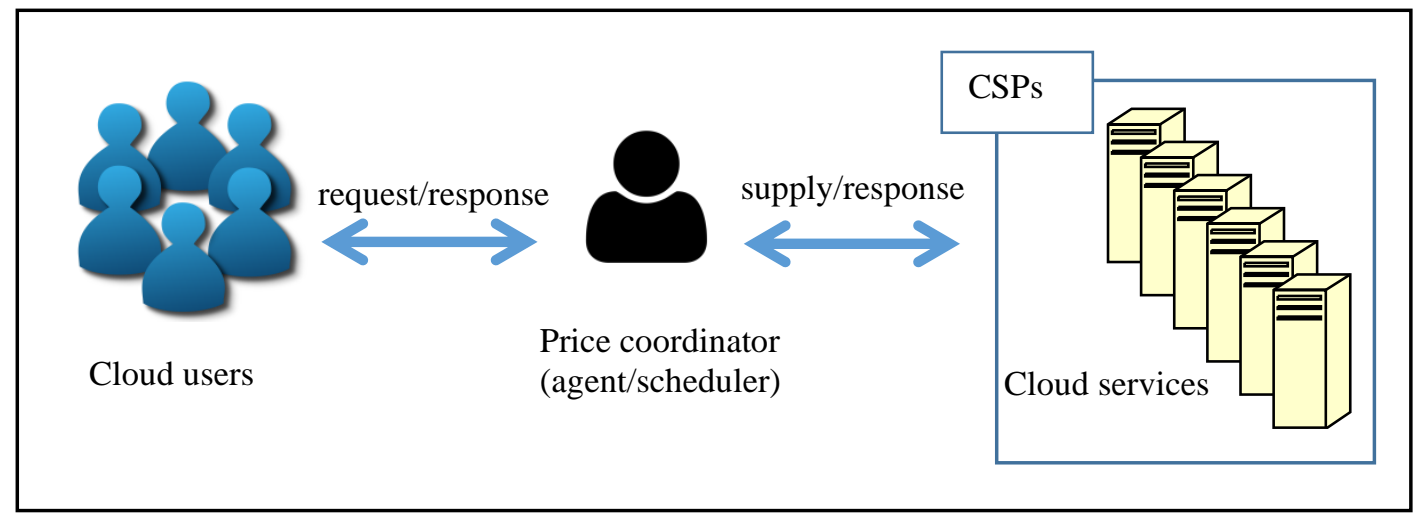

Fig. 1. The Market

\subsection{Service Insfrastructure}

For this work we consider the Cloud service refers to any of the services from the provider that can satisfy the users. Specifically, the economic-based middleware platform coordinates the service agreement between providers and users for identifying the suitable price range of requested service. The Cloud services in this study are charged based on a service value. The service value is not necessary in dollar (\$) where it can represent in variable instances price e.g., time, volume, and reward. Initially, users submitted the service request and waited the response (the price range) from the price coordinator before agreed to rent the service.

The Cloud price coordinator evaluates the service request by the users to match with the service supply from the providers. The SLA's output or service instance is then delivered to the user in the form of contract basis. The service only supplied when the instance is verified and agreed by the user. For each service request from the users, a service preference is given by,

$$
\operatorname{Sreq}_{i}=(\mathrm{dur}, \mathrm{req}, \mathrm{blim})
$$

, where dur refers to duration for leasing the service, req is service requirement descriptions (e.g., storage or CPU) and blim is budget limit that sets by user for paying the service, respectively. For each user's request, it aims to reach the service price within its budget. Meanwhile, the service provider identified a reserve value for its service, given as

$$
\operatorname{Rval}_{j}=\left(c^{i n i}, \text { hist, feat }\right)
$$


, where $c^{i n i}$ is an initial service cost, hist is the performance history in percentage (i.e., higher percentage refers to better performance) and feat refers to special feature of the service, e.g., static, or dynamic service capacity, respectively. Both hist and feat specifically reflects the service revenue where the capability of the service has a linear relationship with the profit that aims to gain by the provider. The provider mainly intentions to maximize its profit while increasing the services utilization.

\section{General Equilibrium Theory for Pricing Agreement Process}

In this section, we describe two agreement procedures that involved in the costing scheme. First is the General Equilibrium Theory (GET) based pricing agreement for forming equal in supply (service) and demand (requirement). Second agreement is related to price ranging process in identifying the exact service price.

\subsection{Economic Interactions through GET}

General Equilibrium Theory (GET) is a theoretical framework that explores solutions of economic equations and their properties for interdependent market [1, 12]. GET works in economy-wide interactions that highlights the theory of competitive market behaviour. It can be applied to study almost any issues $[6,12]$. It is a theoretical framework that explores solutions of economic equations and their properties for interdependent market. Through GET the demand should equal with the supply during market interaction process. It also supports a distributed method for efficiently allocating tasks and resources among agents based on market prices.

Note that, the nature of the Cloud computing environment consists of variety of entities (i.e., resources, users' demands). It makes the scheduling decisions of that entities are either based on dependent or independent policies. There are several independent entities that might be aiming at optimizing their own objectives rather than the performance of the system [19, 20]. Meanwhile, there are some entities that willing to cooperate and share the decisions' strategies to others for goals without degraded their performance. Such environment simultaneously keeps an eye on the global performance of the system. Our system model employed the interdependent scheduling approach where there is an agent (i.e., price coordinator) that plays a best response to the current price and allocation in the system (market), without effect of its own actions on the future state of the market.

In this work, we employed GET model of competitive market behavior to represent Cloud computing that involve frequent buying, selling, trading, and exchanging behaviors between service providers and users. We assume that the market behaviors (e.g., supply and demand) are completely defined before starting to form the agreeable service price. Specifically, there are $i$ users and $j$ service providers in the market; hence, market interaction process is a tuple (Supply S, Demand D, and Resource R). It is also assumed that $\mathrm{D}_{i}>0$ where there is always service request in the market. The form of market interaction in the first agreement for balancing the supply and demand given as follows:

Agreement I:

$$
S_{j}(R) \geq D_{i}(R) \text { and } D_{i}(R)>0
$$

; given that the service price must in positive value, $p_{R} \geq 0$ 
Agreement I can be considered as market environment that aims to build and maintain successful relationships between providers and users. Note that if the service provider reduces its supply then the price of service $p_{R}$ is increased by the value of positive demand. This Agreement I further help in ensuring the equilibrium supply and demand in the market. Therefore, once the interaction and market behaviors are successfully assembled, it is assumed that the market entities are ready for price adjusting.

\subsection{Formation of Price Range}

Our pricing formation strategy aims to find floor and ceiling prices of available services that serve as a price range. Specifically, once the price coordinator has constructed the minimum and maximum prices, it then will be used as service price indicator to charge the users on respective service. The floor and ceiling price values or price range in our work is not explicitly involved in final decision of the actual service price that formed by the provider. Specifically, the service provider charges the service by using the price $p_{R}$ that must accordance with $p_{R} \epsilon$ $\left[p_{R}{ }^{\text {floor }}, p_{R}{ }^{\text {ceiling }}\right]$. It is evident that each provider is necessitated to select the actual price in such range while maintaining a non-negative gross profit margin (i.e., more than its initial $R v a l_{j}$ ). The price adjustment function modifies the initial prices $p_{R}$ by following the rule of market interaction in Agreement I (i.e., $S_{j}(R) \geq D_{i}(R)$ and $p_{R} \geq 0$ ) and it continues until equilibrium price is achieved; i.e., the fixed point is determined. Note that, the service supply from the providers is associated with service reserve value or utility while the users requesting with their service's preference. Therefore, in the second agreement the market aims to balance supply-and-demand according to provider profit and user expense defined as:

Agreement II:

$$
\max \operatorname{profit}_{\mathrm{i}}(R): \operatorname{init} R v a l_{j} \leftrightarrow \min _{\operatorname{expense}}(R): \operatorname{init}_{\mathrm{i}} \operatorname{ereq}_{i}
$$

Agreement II drives the objective of market interaction between providers and users. It means that the provider cannot supply the service with a lower amount than its capacity (i.e., reserve value) and the user are always aim for the service price that meets their budgets. In response to Agreement II, both providers and users shared their information with the price coordinator for constructing the price range in support of profit and expense considerations.

In regards the market environment as the input and market objective as the output, the price coordinator then able to form a relationship between users' demands and providers' profits for achieving transparency and fairness in service price charges. The relationship between user and provider through profit-demand consideration had result adaptive agreement process for developing the service price range (i.e., minimum price and maximum price).

Therefore, we extend the (1) and (2) to define price range that comply Agreement I and Agreement II as:

$$
\left\{\text { max } \mid \text { Supplyt }: \sum(\text { Rvalj)rc } \mid\} \geq\left\{\text { min } \mid \text { Demandt }: \sum(\text { Sreqi }) r c \mid\right\}\right.
$$

where,

$$
r c=(1,2,3 \ldots R) .
$$

It means that the agreeable service price must be complied with both Agreement I and II so that the identified price meets market behaviors either it is a busy market or relax market. Meanwhile, it is able to fulfill both CSPs and users' needs and minimizing the market conflicts. 
Once the (optimal) actual price value is satisfied, the Cloud market makes it possible to execute dynamic resource provisioning in a fast and efficient manner for better business plan.

\section{Results and Discussions}

This section describes the performance evaluation using experimental approach. We also study the effectiveness of price range strategy on several market behaviors.

\subsection{Evaluation Methodology}

In this experimental evaluation, we identified three types of service capacities according to two different services (i.e., computing and storage services). The characteristics of service capacity are determined based on the measurement in [1] that used in our simulation as the available services in the market (Table 1).

In our simulations, the service providers are randomly generated from uniform distribution ranging from 10 to 20 . All service providers in our simulation are agreeable to participate without receiving any service incentive. The service $\operatorname{cost} c^{i n i}$ is included execution cost, maintenance cost and administration cost that set to be randomly distributed within $[0.05$, $0.25]$. Note that $c^{i n i}$ of the Extra-large ${ }^{c / s}$ is always higher than $c^{i n i}$ Normal $^{c / s}$. The initial service cost satisfies with the service characteristics that used in this work.

Table 1. Service Characteristics for Each Service Group

\begin{tabular}{c|c||c}
\hline $\begin{array}{c}\text { Service } \\
\text { characteristics }\end{array}$ & $\begin{array}{c}\text { Computing } \\
\text { Services, } \boldsymbol{C}\end{array}$ & Storage Services, $\boldsymbol{S}$ \\
\hline Normal $^{c / s}$ & $1 \mathrm{PE}$ at $1 \mathrm{GHz}$ & $1.5 \mathrm{GBs}$ \\
\hline Large $^{c / s}$ & 4PEs at $1 \mathrm{GHz}$ & $7.5 \mathrm{GBs}$ \\
\hline Extra-large & Percentage of $8 \mathrm{PEs}$ & $15 \mathrm{GBs}$ \\
& at $1.5 \mathrm{GHz}$ & \\
\hline \hline
\end{tabular}

Each user dynamically submits their demands in Poisson distribution with a mean of 5time units. The lease duration $d u r$ selecting randomly from the following set: $\{2.5,5.8,10.5$, $15.8,25.5,60.8$, and 90.5$\}$. These $d u r$ values are defined in prior through our preliminary experiment during setting-up the Cloud market. The requested services are uniformly distributed accordance to characteristics defined in Table 1; normal, large, or extra-large services. The budget limit is generated based on the expected execution time exet that we assume can be provided by the user using job filing, analytical models or historical information [23].

\subsection{Performance Metrics}

- User satisfaction rate:

It is defined as the ratio of service charges and budget limit. The service charges refer to different between maximum and minimum prices.

- Provider profit:

We define profit of service provider as total revenue divided by utilization rate $R U$ (i.e., $R U=$ busy $/($ busy $+i d l e)$ where busy is the total time of service usage and idle is total idle 
time of service, respectively.) The revenue is calculated as the different between provider's initial service (cost) value and agreeable price.

\subsection{Results}

In order to apply our costing scheme, we set several of market behaviors. It means to study on how the agreement procedures (i.e., Agreement I and II) are effectively fabricated in reaching the optimal service price. These agreements provide a price negotiation platform where the analysis of agreeable prices is recorded to assess factor of market satisfaction. Due to both agreement procedures are take into account supply and demand concepts, it is significant to measure the suppliers (CSPs) and requestors (users) fulfilment in a separated view.

In this experiment, we compare our costing scheme based on three market behaviors, given in Table 2. The heterogeneous and homogenous supplies rely on the service characteristics offers in the market. Meanwhile, dynamic, and static demands refer to behavior of incoming requests from users. The contestable behavior means the market is in chaos with unpredictable service performance that difficult to expect its reliability and there is also substantial load traffic with users' requests. In busy behavior, the market is loosed in the load traffic because all requests are identical and can be effectively scheduled for better resource provisioning. Otherwise, it considered as relax behavior.

Table 2. Type of Competitive Market

\begin{tabular}{c|c||c}
\hline \hline Market Behaviour & Supply Feature & Demand Feature \\
\hline Contestable & Heterogeneous & Dynamic \\
\hline Busy & Heterogeneous & Static \\
\hline Relax & Homogenous & Static \\
\hline \hline
\end{tabular}

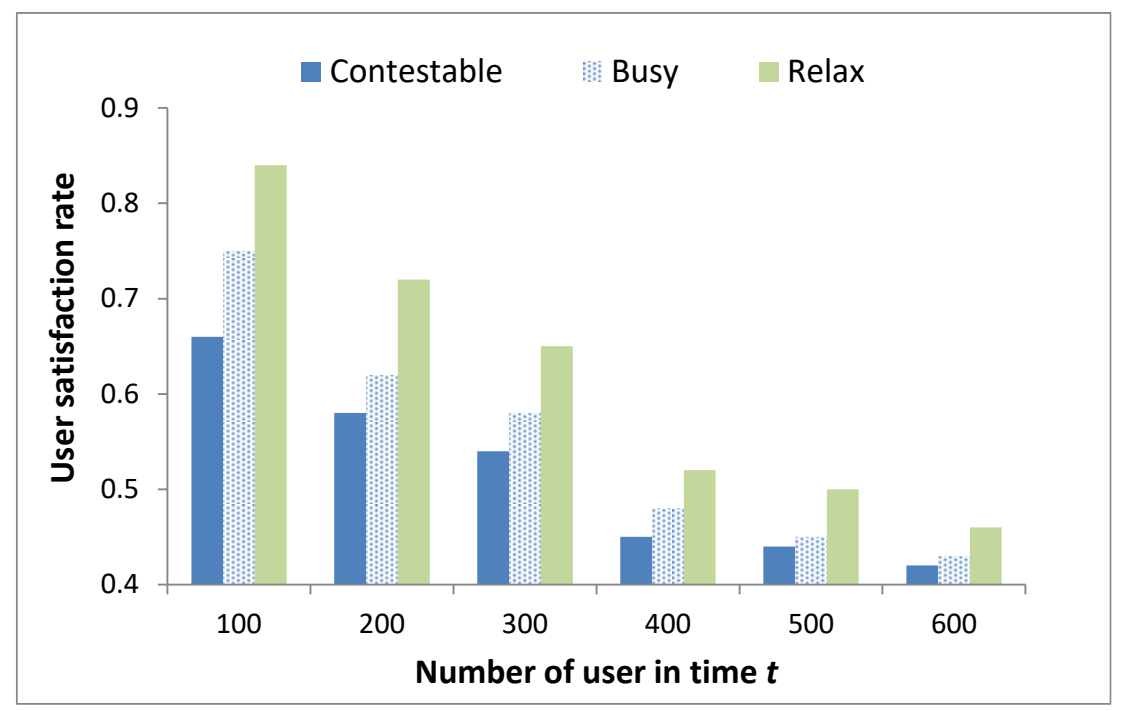

Fig. 2. User satisfactory rate between market behaviors 
Fig. 2 shows that all market behaviors have reached user satisfaction rate more than $40 \%$. Interestingly, the pattern of user satisfaction rate does not significantly differ when there is growth in the number of users as observed to be about $15 \%$ on average. It is due the fact that the price range developed to satisfy budget constraint of users. Implicitly, it indicates the successfulness of the price coordinator's role in executing the negotiating process.

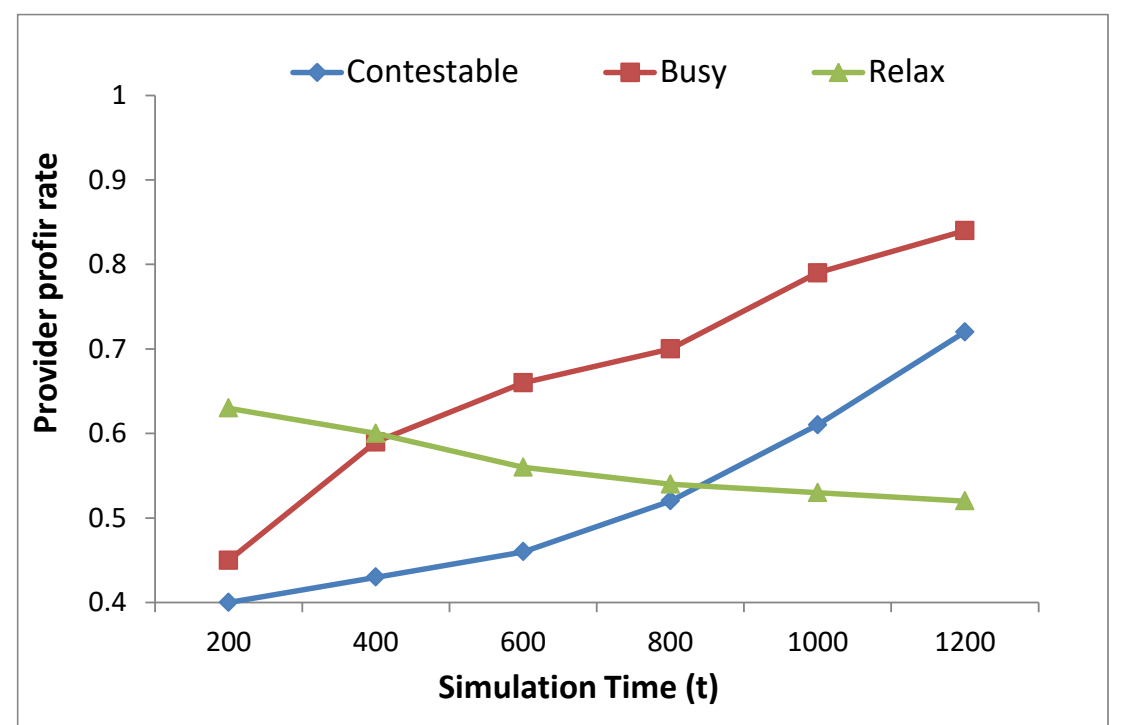

Fig. 3. Provider profit rate between market behaviors

In Fig. 3 we plotted provider profit rate against simulation time. We aim to analyse the providers' profit continuity within time duration. It clearly shows that Contestable, Busy and Relax-markets have contradictory performance with difference in plotting pattern. Contestable-market illustrates that the provider profit is lower than Busy-market while Relaxmarket is shown linear reduction curve. It is demonstrated that our price ranging strategy can work in variability on the service supplies. It also showed (given at Fig. 3) that the equilibrium point reached at 2-conditions simulation times at

i) $400 t$ and

ii) $800 \mathrm{t}$

In the first equilibrium state it is indicated crossed between Busy-market and Relax-market, while in the second equilibrium point showed between Contestable-market and Relax-market. Due to both market behaviors dealt with different supply-and-demand states (Table 2), we extend the simulation time by assessing the successful negotiation rate (is given as the number of users with agreeable prices divided by the total number of negotiations involved) against the number of users in the system. We used the same number of users at both time frames for making fair comparison. It shown in Fig. 4 and Fig. 5 that there are slightly different in term of beating Relax-market in both equilibrium points. 
During $\mathrm{t}=400$, there is high success rate in price negotiating process. It means that the users are satisfied more with the prices that been agreed in Busy-market compared to Relax-market. Usually the Busy-market increases the providers' profits, but surprisingly due to successful negotiation the users satisfied with the prices that been charged. Implicitly, there is no significant complaint on the profit gained by the CSPs if the users' demands are fulfilled.

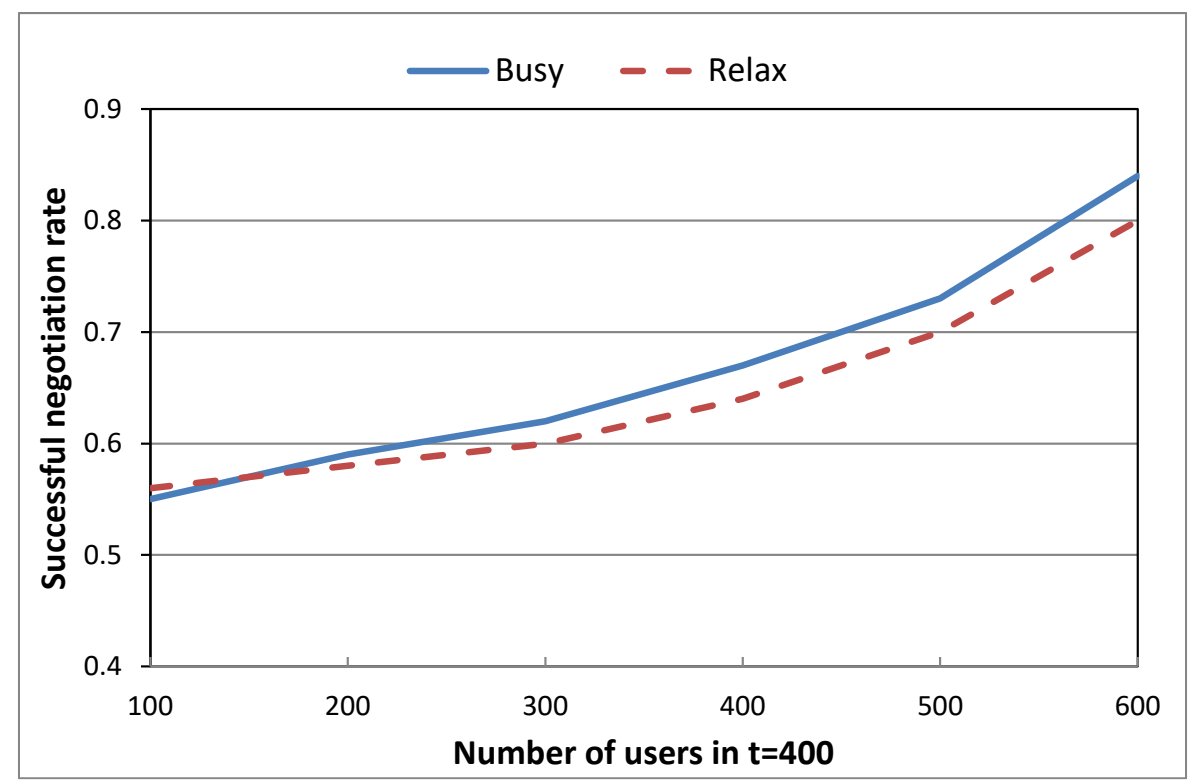

Fig. 4. Negotiation for the right price in equilibrium $t=400$

It does not happen in $\mathrm{t}=800$ where the prices of Relax-market that agreed are merely met users' expectations at the earlier phase in the simulation. In the later phase, the prices in both markets are comparable where the Contestable-market reached better satisfaction. Such result happens due to in the second agreement (Agreement II) is established by considering the equal profit and budget attributes. From the experiment, it revealed that with highly heterogeneous and dynamic in supply and demand, the market is able to gain better negotiations because of many preferences and options.

It was noted that during resource allocation decisions in Cloud computing each service provider aims at optimizing its own objectives (e.g., profit) while increasing the performance of system. Such situations had called for fair costing scheme in managing equilibrium demand and supply where it is significant for securing Cloud computing reputation. While the providers sustaining the performance, the users have their right to receive the suitable service price. The equilibrium supply-demand in Cloud competitive market and agreeable service price are significant criteria to reduce conflicting needs between CSPs and users. 


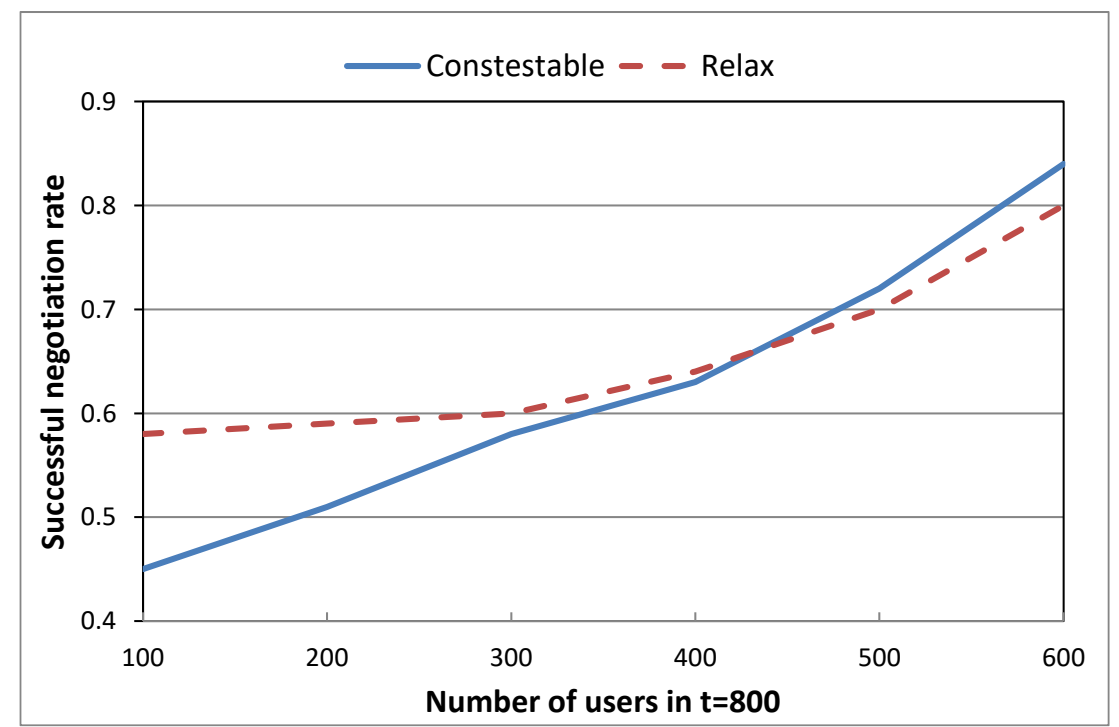

Fig. 5. Negotiation for the right price in equilibrium $t=800$

We further compared our costing scheme with pricing strategies proposed by the authors in [5] and [22]. Specifically, all strategies are applied different costing schemes to determine the optimal price but working on the same market behaviours; complement between providers and users. Since our GET based costing scheme performs by the price coordinator, we have revised the other both costing schemes to fit into our cost model. In the comparison, their equilibrium prices are obtained only when the market interaction between user and providers is established. However, for the sake of fairness, we remained the role of the service providers in the models; monopoly type of providers [5], as Analytic Price, and reward basis providers [22], as $R L$ Price. We chose the Contestable-market behaviour in this comparison because the real Cloud market has various services to be matched with various demands.

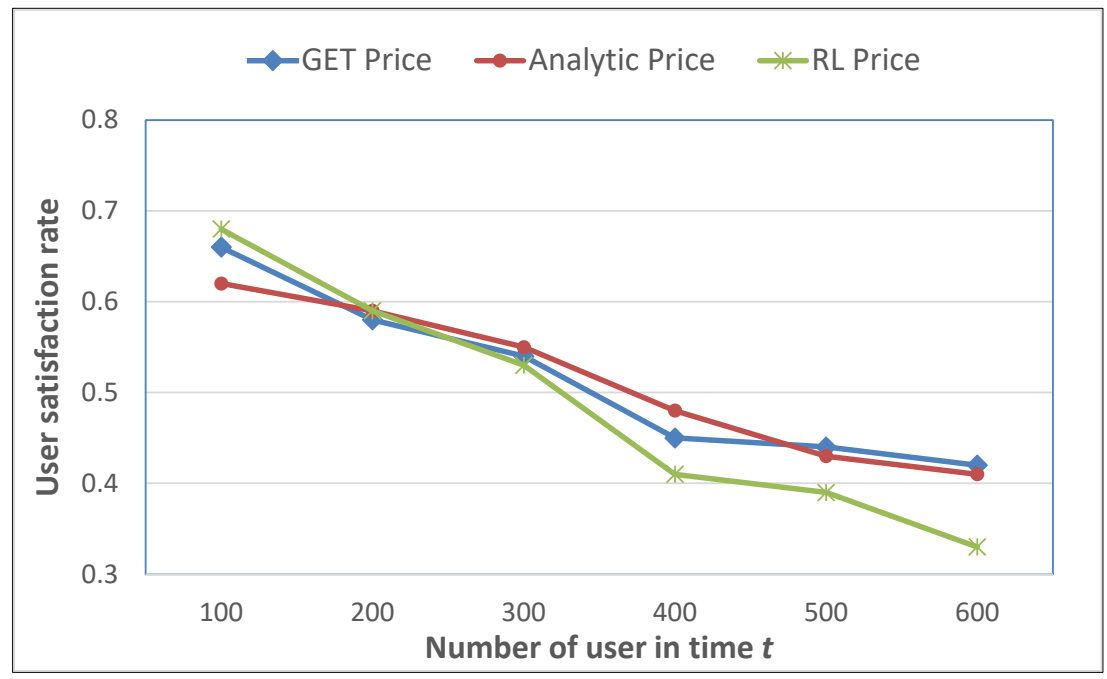

Fig. 6. User satisfactory rate under different costing schemes 
Fig. 6 depicts that all schemes have reached their success rate more than 50\% during small number of users in the market. Notwithstanding this observation, it can be seen that results of GET Price is very close to $R L$ Price under least loads, and comparable with Analytic Price under heaviest loads. It is because the costing schemes in both approaches tends to reach the optimal price at a particular number of users. For example, in the Analytic Price, the model focuses on social welfare hence satisfying as many users as possible is part of their objectives. Meanwhile, the $R L$ Price scheme is a bit tight to deal with good users' satisfactions under heaviest loads due to the price determination biased towards the requirements of the service provider.

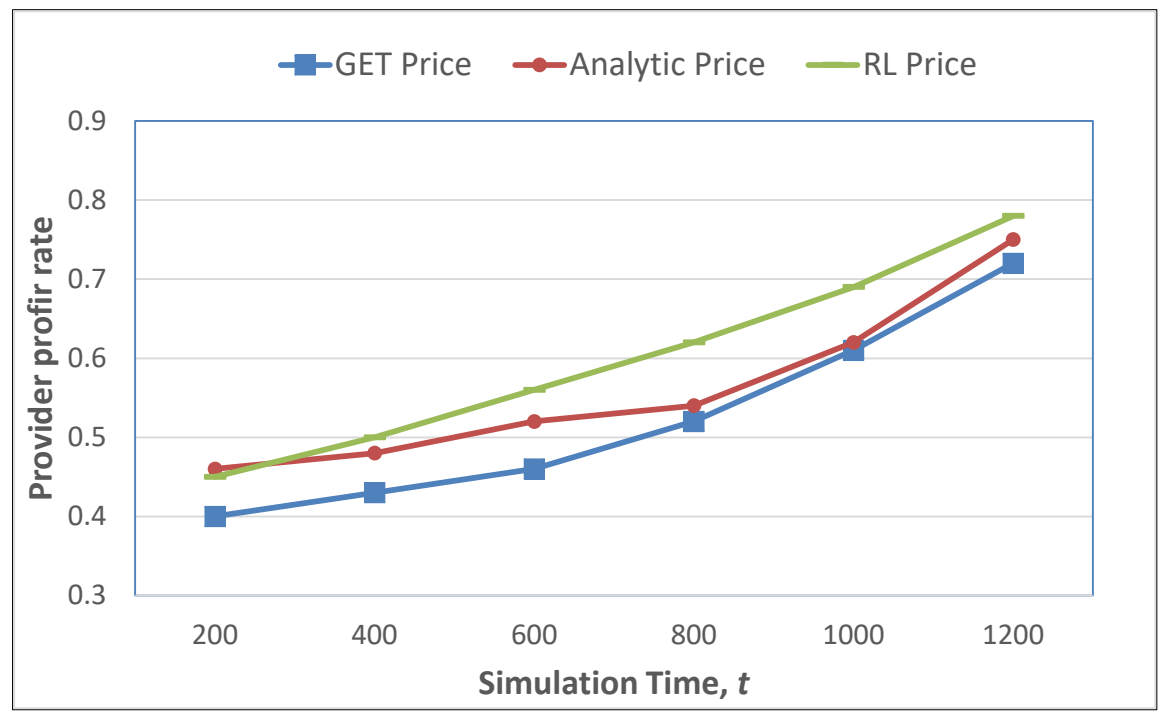

Fig. 7. Provider profit rate under different costing schemes

Fig. 7 shows the provider profit rate that is plotted against simulation time. The RL Price obtains appealing profit rate compared to two other costing schemes, with $60 \%$ profit on average. This performance can be explained by the pricing determination used in their market where the time slot is applied for allocating special treatment users. Those users are willing to rent the service with higher price than the original price offered by the providers. It implicitly increases the providers' profit. On the other hand, it also indicates that our scheme GET Price sustains performance optimization with satisfactory profit, $55 \%$ on average.

Note that, the successful price negotiating process between the CSPs and users might be reached through the existing SLAs $[8,18-20]$. However, it is unsure either the final service prices are reckoning by the supply-and-demand interaction. It can happen in the situation when the SLAs is met but victimised the users by high in price charging. Therefore, in our closing experiment, we study the impact of price charging over the SLAs negotiation. We executed the agreement platform (i.e., Agreement and Agreement II) into Cloud market interaction. At this time, we used the Free-market (random setting for supply and demand features) for comparing the agreed prices over supply-demand ratio. The supply-demand ratio gains from the user satisfactory rate and provider profit rate of the Free-market setting.

As shown in Fig. 8, in the early simulation time there are significant difference between the match price and the supply-demand ratio. This is can be explained by there are many users and providers are still negotiating the right price for their supplying and demanding activities in the active markets. We envision the realization of the price range with the support of 
transparent information implicitly improves trustworthiness towards Cloud-computing platform.

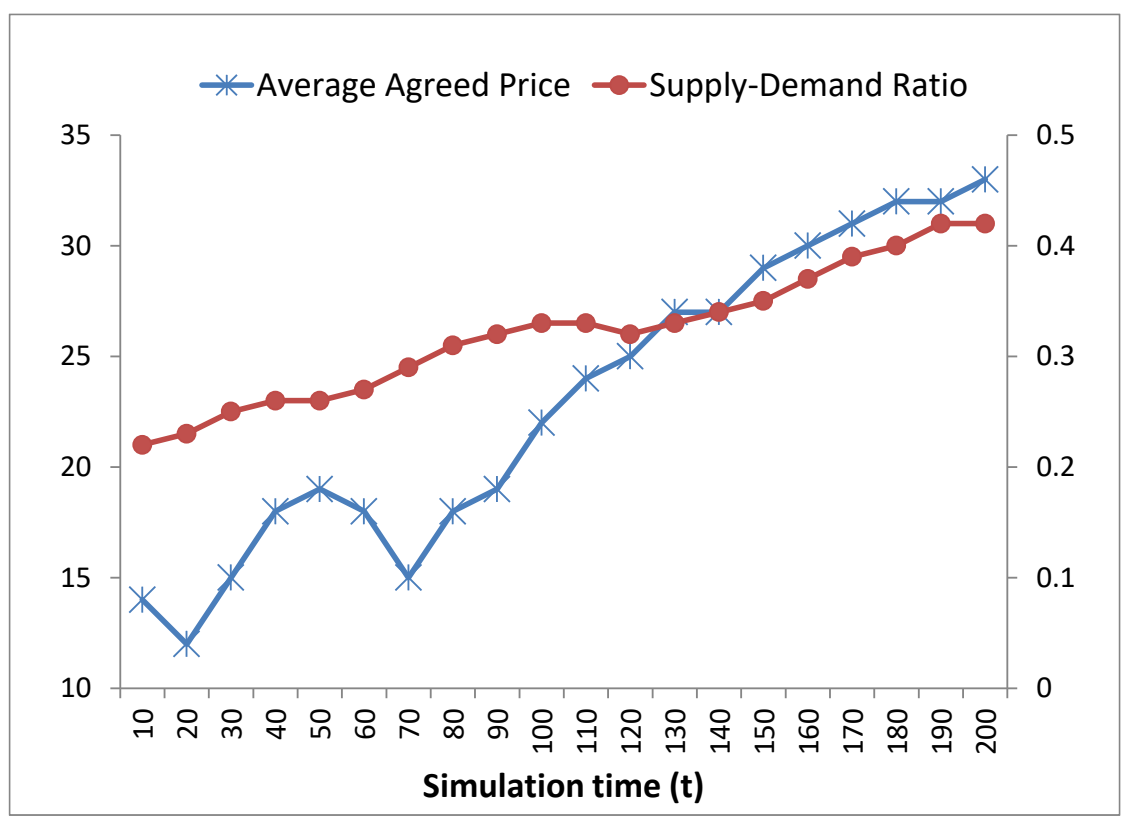

Fig. 8. Agreed price vs. Supply-demand ratio in busy market

Our pricing negotiating process (i.e., Agreement I and II) is designed in respect to the willingness of the CSPs and users to be participated in the market. It is considered as a solution in Cloud computing for securing fair pricing in competitive market environment. In this sense, the users unable to choose the Cloud services from the CSPs that not joining the market, and it by some means degraded the service accessibility. On the other hand, the market gives a platform for the CSPs to promote their new services if they are newcomers as the Cloud providers. Practically, the Cloud users get benefits from the fair price charging. Explicitly, our costing scheme able to reach a win-win agreement with efficient negotiating process.

\section{Conclusion}

Considering high volume of mixed users' demands and the diversity of services offered; pricing fairness has become necessary and challenging. In this paper, we addressed the pricing fairness that form through General Equilibrium Theory (GET). Such price formation aims for assisting price leasing agreement between market participants, i.e., providers and users. In our costing scheme, the service price is determined and formed in a price range. The maximum and minimum prices are established and relied on both initial providers' revenues and users' budgets. The incorporation of GET into pricing agreement improves transparent information in the user-provider interaction. Based on the results from our experiments that take into account both user satisfaction and provider profit, it confirms with our claims. The effective costing scheme through fair agreement procedure can strengthen transparency and accountability in Cloud computing. It also provides a door for improvement in pricing interchange and negotiation of inter-CSPs that are to be addressed through further research. 


\section{References}

[1] R. Pal and P. Hui, "Economic models for Cloud service markets: Pricing and Capacity Planning," Theoritical Computer Science, vol. 496, pp. 113-124, 2013. Article (CrossRef Link)

[2] M. Hussin, A. Abbulah, and R. Latip, "Agent-Based Pricing Determination for Cloud Services in Multi-tenant Environment," International Journal of Computer and Communication Engineering, vol. 3, no. 6, pp. 454-459, 2014. Article (CrossRef Link)

[3] M. H. Ghahramani, M. Zhou, and C. T. Hon, "Toward cloud computing QoS architecture: Analysis of cloud systems and cloud services," IEEE/CAA Journal of Automatica Sinica, vol. 4, no. 1, pp. 6-18, 2017. Article (CrossRef Link)

[4] P. Cong, G. Xu, T. Wei, and K. Li, "A Survey of Profit Optimization Techniques for Cloud Providers," ACM Computing Surveys (CSUR), vol. 53, no. 2, pp. 1-35, 2020. Article (CrossRef Link)

[5] S. H. Chun, "Cloud Services and Pricing Strategies for Sustainable Business Models: Analytical and Numerical Approaches," Sustainability, vol. 12, no. 1, 2019. Article (CrossRef Link)

[6] B. Varghese and R. Buyya, "Next generation cloud computing: New trends and research directions," Future Generation Computer Systems, vol. 79, pp. 849-861, 2018. Article (CrossRef Link)

[7] R. Han, M. M. Ghanem, L. Guo, Y. Guo, and M. Osmodn, "Enabling cost-aware and adaptive elasticity of multi-tier cloud applications," Future Generation Computer Systems, vol. 32, pp. 8298, 2014. Article (CrossRef Link)

[8] S. Kansal, H. Kumar, S. Kaushal, and A. K. Sangaiah, "Genetic algorithm-based cost minimization pricing model for on-demand IaaS cloud service," The Journal of Supercomputing, vol. 76, pp. 1536-1561, 2018. Article (CrossRef Link)

[9] P. Dixon and D. Jorgenson, Handbook of Computable General Equilibrium Modeling $1^{\text {st }}$ Edition. North Holland: Elsevier, 2012.

[10] L. Dierks and S. Seuken, "Cloud pricing: The spot market strikes back," in Proc. of 2019 ACM Conference on Economics and Computing, 2019. Article (CrossRef Link)

[11] A. Kaufmann and K. Dolan, "Price Comparison: Google Cloud Platform vs. Amazon Web Services," The Enterprise Strategy Group, Inc. 2015.

[12] B. P. Peddigari and G. Phadke, "Windows Azure-The Cloud Computing Platform," Tata Consultancy Services (TCS), 2011.

[13] S. Williams, "IBM Cloud Services Balancing compute options: How IBM SmartCloud can be a catalyst for IT transformation," IBM Cloud, 2011.

[14] C. Wu, R. Buyya, and K. Ramamohanarao, "Cloud pricing models: Taxonomy, survey, and interdisciplinary challenges," ACM Computing Surveys (CSUR), vol. 52, no. 6, pp. 1-36, 2019. Article (CrossRef Link)

[15] D. T. Nguyen, L. B. Le, and V. Bhargava, "Price-based resource allocation for edge computing: A market equilibrium approach," IEEE Transactions on Cloud Computing, 2018. Article (CrossRef Link)

[16] Y. Jafari and W. Britz, "Modelling heterogeneous firms and non-tariff measures in free trade agreements using Computable General Equilibrium," Economic Modelling, vol. 73, pp. 279-294, 2018. Article (CrossRef Link)

[17] L. Dierks and S. Seuken, "The Competitive Effects of Variance-based Pricing," in Proc. of $29^{\text {th }}$ International Joint Conference on Artificial Intelligence, pp. 362-370, 2020. Article (CrossRef Link)

[18] N. Dimitri, "Pricing cloud IaaS computing services," Journal of Cloud Computing, vol. 9, no. 14, 2020. Article (CrossRef Link)

[19] R. Makhlouf, "Cloudy transaction costs: a dive into cloud computing economics," Journal of Cloud Computing, vol. 9, no. 1, 2020. Article (CrossRef Link)

[20] C. Wu, R. Buyya, and K. Ramamohanarao, "Modelling cloud business customers' utility functions," Future Generation Computer Systems, vol. 105, pp. 737-753, 2020.

Article (CrossRef Link) 
[21] X. V. Doan, X. Lei, and S. Shen, "Pricing of reusable resources under ambiguous distributions of demand and service time with emerging applications," European Journal of Operational Research, vol. 282, no. 1, pp. 235-251, 2020. Article (CrossRef Link)

[22] P. Cong, J. Zhou, M. Chen, and T. Wei, "Personality-guided Cloud Pricing via Reinforcement Learning," IEEE Transactions on Cloud Computing, p. 1, 2020. Article (CrossRef Link)

[23] M. Hussin, Y. C. Lee, and A. Y. Zomaya, "Reputation-based Resource Allocation in MarketOriented Distributed Systems," Algorithms and Architectures For Parallel Processing : Lecture Notes in Computer Science, pp. 443-452, 2011. Article (CrossRef Link)

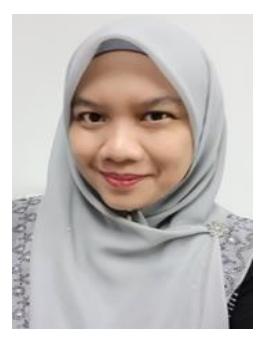

Associate Prof. Dr. Masnida Hussin is a senior lecturer at the Department of Communication Technology and Network, Faculty of Computer Science \& IT, University Putra Malaysia, Malaysia. She received her Ph.D. from University of Sydney, Australia in 2012. Mainly her research interest is resource management such as scheduling, allocation and edge analytic for large-scale parallel and distributed computing. She involved in several network projects such as Cloud computing, network cloudification and green computing. She is a member of the IEEE since 2008, also has published several numbers of papers that related to parallel and distributed computing. She also become editorial board member/reviewer in several national and international journals.

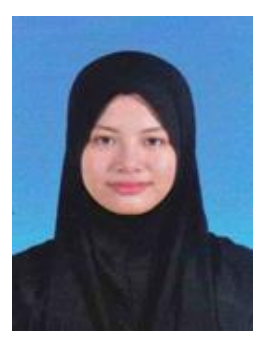

Siti Fajar Jalal studied in Technical University of Malaysia Melaka (UTeM) before graduating in 2012 with Bachelor of Computer Science (Computer Networking). She received her Master in Computer Science (Distributed Computing) from University Putra Malaysia in 2014. Her research orientation is mainly towards Cloud pricing and scheduling using scientific computing.

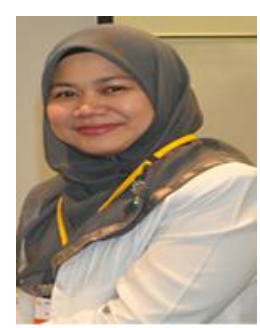

Associate Prof. Dr. Rohaya Latip is an Associate Professor at Faculty of Computer Science and Information Technology, University Putra Malaysia. She holds a Ph.D. in Distributed Database in year 2000. She is currently the Head of Department of Communication Technology and Network. She served as an Associate Professor at Najran University, Kingdom of Arab Saudi (2012-2013). She is the Head of HPC section in Institute for Mathematic Research (INSPEM), University Putra Malaysia (2011-2012) and consulted the Campus Grid project and also the Wireless for hostel in Campus UPM project. Her research interest includes Big Data, Cloud and Fog-edge Computing, Network management, and Distributed database. 